Bio-grafía. Escritos sobre la Biología y su Enseñanza. ISSN 2027-1034

Número Extraordinario. p.p. 293-301

Memorias del Primer encuentro ambiental Universidad, ambiente y sustentabilidad: experiencias y prácticas.

\title{
ACCIONES SOCIALES QUE PERJUDICAN LA CONSERVACIÓN DE LOS PÁRAMOS DE SUMAPAZ Y CHINGAZA.
}

\section{Resumen}

Acevedo Vanessa, Gamboa Camila, Martínez Angélica, Sánchez Paula ${ }^{1}$

La implementación de est ${ }^{2}$ e taller, tuvo como propósito vincular la relación hombre-naturaleza desde la reflexión del impacto directo o indirecto que posee la sociedad sobre los páramos de Sumapaz y Chingaza, desde una perspectiva de sustentabilidad y conservación de estos entornos, demostrando la importancia de dicha relación y las afectaciones a otros ambientes. En tal sentido, es importante identificar aquellas acciones que ha generado el hombre desde su cotidianidad a la afectación de los ecosistemas de los Páramos de Sumapaz y Chingaza. Igualmente, el taller se fundamentó en encontrar las causas del deterioro de los páramos que han generado las actividades humanas, desde escenarios sociales, económicos, tecnológicos y culturales, a través de acciones como la deforestación, la caza indiscriminada de especies, la agricultura, la quema de la vegetación, la contaminación de fuentes hídricas, la minería, etc.

La fragmentación que se ha evidenciado en los páramos actualmente, nos invita a reconocer las concepciones y prácticas que tiene la sociedad en los páramos, ya que son ellas las que afectan directamente la estabilidad y conservación de estos ecosistemas que son de gran importancia para nuestra ciudad. A través de una experiencia educativa se propuso aportar en la reflexión sobre prácticas sustentables a favor del reconocimiento de los páramos, que son ecosistemas vitales para la conservación de la biodiversidad.

${ }^{1}$ Universidad Pedagógica Nacional. - Profesores en formación inicial-

Departamento de Licenciatura en Biología.

dbi_mamartinezr015@pedagogica.edu.co 
Bio-grafía. Escritos sobre la Biología y su Enseñanza. ISSN 2027-1034

Número Extraordinario. p.p. 293-301

Memorias del Primer encuentro ambiental Universidad, ambiente y sustentabilidad: experiencias y prácticas.

Palabras Claves: Páramo, Ecosistema, Ambiente, Sustentabilidad, Conservación.

\section{Abstract}

The workshop was done with the purpose to link the importance of the relation man-nature with the reflection about direct and indirect impacts that society has in the sustainability and conservation of Sumapaz and Chingaza area. In this sense, it is important to identify those actions that people made from this daily life to affect those ecosystems. Likewise, the workshop was based on finding the causes of deterioration of moorlands due to human activities, from social, economic, technological and cultural scenarios, through actions like deforestation, hunting, agriculture, burning of forest, water pollution, mining etc.

Fragmentation in moorlands involves us all to recognize the concepts and practices that society has in those ecosystems, since those relationships affect the stability and conservation of those important areas for our city. Through an educational experience set out to bring in thinking about sustainable practices in favor of moors, and conservation of biodiversity.

Keywords: Moorland, Ecosystem, Environment, Sustainability, Conservation.

\section{INTRODUCCIÓN}

Los páramos son ecosistemas estratégicos pues dan origen al agua fuente de vida y son el refugio de muchas especies endémicas que se encuentran solo en estos ecosistemas, convirtiéndose entonces en lugares únicos y diversos. De esta manera los páramos son funcionan como reguladores hídricos, son reservorios de carbono y propician el nacimiento de innumerables ríos, quebradas o pequeñas fuentes que alientan todo el sistema hídrico y regulan el ciclo del agua. A pesar de que se sabe su importancia, cada día están siendo amenazados por la explotación extensiva a través de prácticas como la ganadería, la agricultura y la minería, sumándose a este escenario la amenaza global del cambio climático.

En esta medida la sociedad parece estar absorta en el nuevo mundo tecnológico, haciendo ver estas problemáticas lejanas, ya que primeramente 
Bio-grafía. Escritos sobre la Biología y su Enseñanza. ISSN 2027-1034

Número Extraordinario. p.p. 293-301

Memorias del Primer encuentro ambiental Universidad, ambiente y sustentabilidad: experiencias y prácticas.

no entiende la magnitud de las intervenciones humanas dentro de los páramos, las políticas que circulan hacen parecer que la mayoría del territorio del páramo está siendo protegido, cuando en realidad solo cierta parte de ellos se encuentra en intervención de cuidado y conservación. Otra concepción que influye en la degradación de los páramos es que estas problemáticas no son abordadas en la escuela, lo que implica en primera medida restar importancia a estos ambientes y en segunda medida informar sobre las problemáticas que estos poseen. El alejamiento de la escuela la realidad imposibilita la asociación de las prácticas cotidianas con su impacto en los ecosistemas de páramo, sin los cuales no sería posible encontrar tanta diversidad como la existente actualmente en la naturaleza.

Teniendo en cuenta las problemáticas que se encuentran en los páramos en diversos contextos es necesario que como futuros maestros reflexionemos frente a cuáles acciones y posturas que se deben tomar para afrontar estas problemáticas. Considerando la necesidad de que los maestros reflexionen, problematicen y se cuestionen frente a las acciones sociales que perjudican la conservación de los páramos de Sumapaz y Chingaza se propuso este taller que pretendió aportar y dar elementos para la recontextualización sobre prácticas sustentables que se pueden adoptar en favor de los páramos como ecosistemas vitales para el cuidado de la vida.

\section{OBJETIVOS DEL TALLER}

- Reconocer las concepciones que tenemos acerca de nuestra relación con el ambiente y las implicaciones que generan a la conservación de la biodiversidad de los páramos Sumapaz y Chingaza.

- Desarrollar una estrategia fundamentada en la conservación de los páramos y su importancia en la sustentabilidad ambiental para los grupos humanos.

- Reflexionar frente a las diferentes acciones que realizamos diariamente y cómo estas afectan a los páramos.

\section{DURACIÓN.}

El taller se realizó en 45 minutos. 
Número Extraordinario. p.p. 293-301

Memorias del Primer encuentro ambiental Universidad, ambiente y sustentabilidad: experiencias y prácticas.

\section{MATERIALES.}

Televisor, biogalería virtual, video "Los Paramos de agua para la vida", pequeñas macetas hechas en cartón, semillas de Eugenia, tierra, Agua.

\section{ACTIVIDADES.}

En la primera parte del taller se realizó una contextualización de las generalidades de los páramos de Sumapaz y Chingaza, para posteriormente generar discusión que introduciendo a los participantes alrededor de las preguntas: ¿Qué importancia tienen los páramos? ¿Por qué proteger los páramos? En la misma medida se buscó que los participantes problematizaran sobre las visiones erróneas que conciernen al páramo como una máquina de producción de agua y entendieran la importancia de este, no sólo por la fabricación de agua sino por ser un ecosistema estratégico que permite la supervivencia de diferentes especies tanto en flora como en fauna, de las cuales muchas de estas especies han desaparecido en otros ambientes, convirtiéndose entonces en un lugar de gran importancia para la conservación. Sumado a esto su función como reservorios de carbono, que, de ser degradados, serían una fuente potencialmente peligrosa de emisión de $\mathrm{CO} 2$ a la atmósfera. Luego se presentaron las principales especies que se encuentran en este hábitat y cuáles están siendo perjudicadas por las acciones del hombre. A partir de esta discusión s presentaron una serie de imágenes en donde se evidenciaba que solo cierta parte de los páramos están siendo protegidos actualmente por Parques Nacionales Naturales y las otras se encuentran intervenidas por malas prácticas que se llevan a cabo por las comunidades y diversas entidades.

Terminando esta parte del taller se presentó un video denominado "Los páramos agua para la vida" con el propósito de que los participantes reflexionaran desde un aspecto histórico, puesto que los páramos han sido reconocidos como ecosistemas sagrados, brindando equilibrio a la naturaleza en el origen de todas las fuentes de agua dulce y posibilitando la protección de todas las formas de vida. También en el mismo video se presentaron cifras significativas del porcentaje de agua que gastan los habitantes de la ciudad de Bogotá de los páramos, cuantos páramos se encuentran en Colombia y cuántas de las especies se están extinguiendo. Estas cifras permitieron reconocer cómo están siendo afectados los páramos 


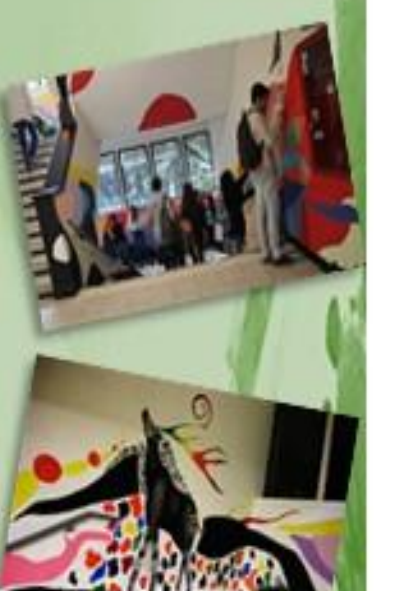

Bio-grafía. Escritos sobre la Biología y su Enseñanza. ISSN 2027-1034

Número Extraordinario. p.p. 293-301

Memorias del Primer encuentro ambiental Universidad, ambiente y sustentabilidad: experiencias y prácticas.

complejizados, perdiéndose de alguna manera la concientización que de tal análisis pudiese generarse y abordarse en la escuela. La mayoría de los participantes reconocieron la ganadería, la agricultura y la minería como principales acciones que perjudican la conservación de los páramos, sin embargo, el taller mostró dichas acciones desde diferentes miradas tanto económicas, socio-políticas, ambientales, históricas que permitieron no verlo como un problema sino ser contemplado como una situación que debe ser abordada en la escuela para ser defendida y protegida de manera urgente.

Durante el taller emergieron diversos comentarios que abarcaron dos aspectos relevantes el biológico y el pedagógico, aspectos que se relacionan directamente con nuestra formación, pues en nuestro papel como futuras licenciadas en biología es primordial generar el enlace entre estos dos aspectos; el biológico se evidenció desde el mismo planteamiento del taller, en donde se apunta a ese reconocimiento de la importancia que poseen los páramos ligado a la posición mundial que posee Colombia frente a estos territorios. Así como reconocerla historia natural-cultural que se ha ido perdiendo con el paso del tiempo, pues los asistentes al taller mencionaron que las primeras culturas indígenas, principalmente la Muisca, mantenían relaciones de cuidado y respeto con estos territorios, apuntando a su supervivencia y al mantenimiento de estos ecosistemas, sin embargo, hoy día la sociedad ha modificado y establecido nuevas relaciones con este territorio, pero en miras de su propio desarrollo y sostenimiento, pensando en sí mismos, sin medir las consecuencias de estas acciones.

Junto a lo anterior, también se evidenció la importancia de este hábitat a nivel mundial y a nivel nacional, puesto que, se reconoció que los estudiantes conocen acerca de las estadísticas de pertenencia de este ambiente en nuestro país, generando una crítica puesto que aunque conocemos y estamos seguros que muchos colombianos también reconocen esta cantidad porcentual, muchas veces se queda en cifras y no se reconoce su valor intrínseco , ni se promueve su cuidado y protección, no solo por la alta cantidad de agua que en él se almacena sino por la biodiversidad que allí se encuentra, su importancia cultural, histórica además de la conductividad que este genera para otras biotas. 
Bio-grafía. Escritos sobre la Biología y su Enseñanza. ISSN 2027-1034

Número Extraordinario. p.p. 293-301

Memorias del Primer encuentro ambiental Universidad, ambiente y sustentabilidad: experiencias y prácticas.

además de crear un vínculo simbólico en dicha siembra, donde la relación con la naturaleza y el compromiso adquirido permiten desarrollar otras dinámicas en cuanto a acciones llevadas a cabo a diario, cada una de las cajas donde se depositó la semilla contaba con la frase "Por más pequeña que sea en su interior guarda mil misterios" Gamboa C (2016)., Los estudiantes lograron reflexionar en cuanto a la gran riqueza ecológica, histórica y cultural que se desborda de los páramos de Sumapaz y de Chingaza, además fueron expuestas las evocaciones de la frase desde su concepto personal encontrándose de manera subjetiva opiniones muy particulares y diversas.

Cabe aclarar que esta temática, se seguirá trabajando dentro de las aulas de clase y todos aquellos espacios no convencionales de enseñanza que permitan reconocer la importancia de los sistemas vivos y la influencia de cada especie sobre los mismos, en especial de la especie humana.

FOTO 1. [Fotografía de Andrés Reyes]. (Bogotá, 2016). Archivos fotográficos del taller: Acciones sociales que perjudican la conservación de los páramos de Sumapaz y Chingaza. Universidad Pedagógica Nacional, Bogotá, Colombia.

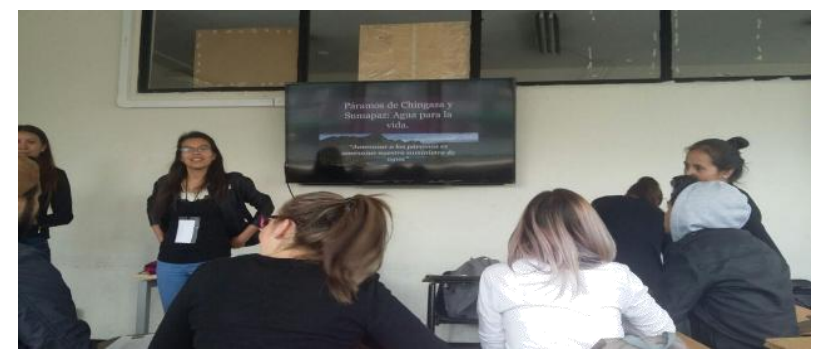

FOTO 2. [Fotografía de Andrés Reyes]. (Bogotá, 2016). Archivos fotográficos del taller: Acciones sociales que perjudican la conservación de los páramos de Sumapaz y Chingaza. Universidad Pedagógica Nacional, Bogotá, Colombia.

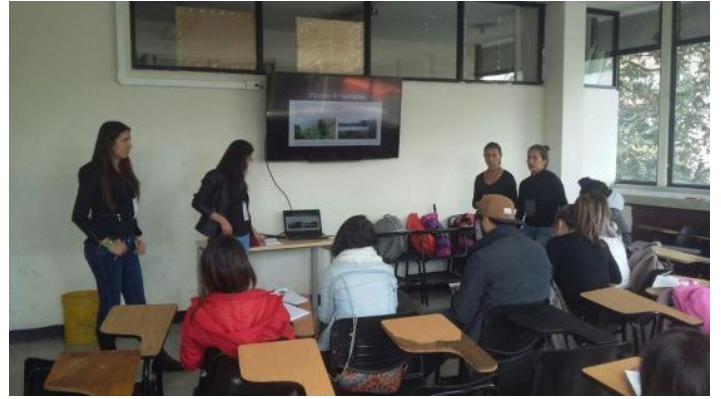


Bio-grafía. Escritos sobre la Biología y su Enseñanza. ISSN 2027-1034

Número Extraordinario. p.p. 293-301

Memorias del Primer encuentro ambiental Universidad, ambiente y sustentabilidad: experiencias y prácticas.

\section{REFERENCIAS BIBLIOGRÁFICAS.}

Gamboa, C. (2016). Reflexiones del taller Acciones sociales que perjudican la conservación de los páramos de Sumapaz y Chingaza. Universidad Pedagógica Nacional, Bogotá, Colombia.

Flores, A. (1992). Los Nevados de Colombia, glaciales y glaciaciones. Instituto Geográfico Agustín Codazzi, Bogotá, Colombia: Análisis Geográficos.

Iriarte, P. (1995). El Páramo un ecosistema de Alta Montaña: Serie Montañas. Bogotá, Colombia: Fundación.

Landsberg, J., Connor, T. y Freudenberger, D. (1999). The Impacts of Livestock Grazing on Biodiversity in Natural Ecosystems. Bogotá, Colombia.

Madriñán, S. (2012). Flora ilustrada del Páramo de Chingaza, Proyecto Páramo Andino Conservación de la diversidad en el techo de los Andes. Bogotá, Colombia.

Morales, M. (2007) Atlas de páramos de Colombia. Instituto de Investigación de Recursos Biológicos Alexander von Humboldt. Bogotá, Colombia.

Rangel, J. (2000). Colombia Diversidad Biótica III. La Región de vida paramuna. Instituto de Ciencias Naturales, Universidad Nacional de Colombia, Bogotá, Colombia.

Ramírez, O. (2013). Reflexiones en torno a la didáctica latinoamericana: aportes pedagógicos críticos de Paulo Freire y Estela Quintar. Antioquia, Colombia.

Reyes, P. (2003). El páramo de Sumapaz, Un ecosistema estratégico para Bogotá, Colombia. 